\title{
Veterans Health System Pathology
}

\section{Gholamreza Taebi ${ }^{1}$, Mohsen Miransari ${ }^{2 *}$}

${ }^{1}$ Supreme National Defense University, Tehran, Iran

${ }^{2}$ Police University, Tehran, Iran

\section{A BSTRACT}

Introduction: With respect to the impact of the health system on the veterans' life and their presence in many different fields, such as political, social, cultural, economical, and technological fields, the present study was aimed to study veterans' health care system to promote their overall health and to evaluate how desirable this system to the veterans. Materials and Methods: The population participated in this research was consisted of 600 experts in the field of health policy and management, legislation and implementation of the health system in martyr foundation, armed forces health services management, and trade association, who have been selected by a stratified random target. The sample size was 234 persons determined using Cochran formula and 247 people was selected for the explanation of the findings. Results: Statistical analysis due to the significant scale tests and items revealed unacceptable statues of veterans' health systems. Conclusion: It is necessary to plan all missing issues in the veteran health system quoted by responders. Furthermore, all new strategies should be managed directly by the administration of the veterans' health system.

\section{Key words:}

1. Health Promotion

2. Veterans

3. Pathology

*Corresponding Author: Mohsen Miransari

E-mail:mmiransari@yahoo.com 


\section{آسيبشناسى نظام سلامت ايثارگران}

غلامرضا طائبى'، محسن مير انصارى זم"

'دانشخاه عالى دفاع ملى، تهران، ايران

'دانشكاه علوم انتظامى، تهران، ايران

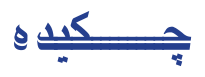

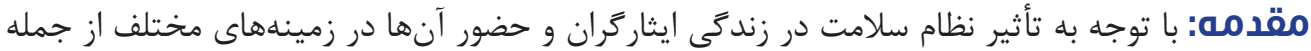

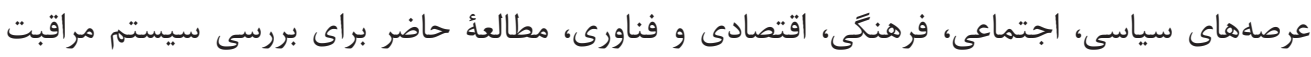

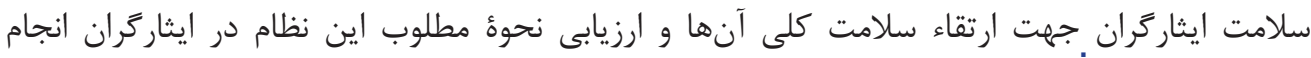

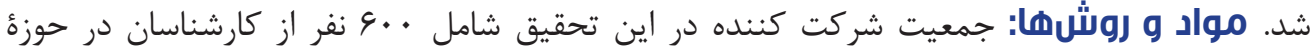

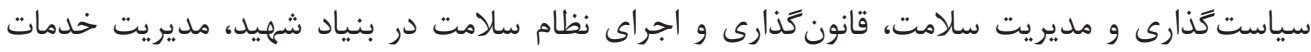

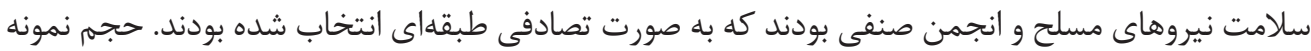

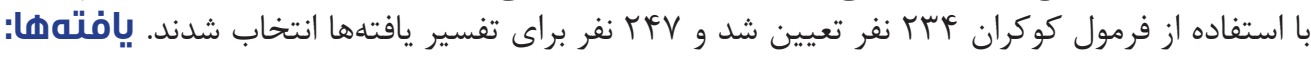

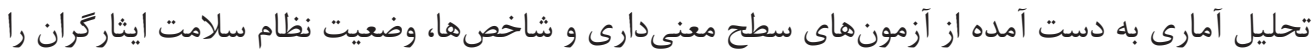

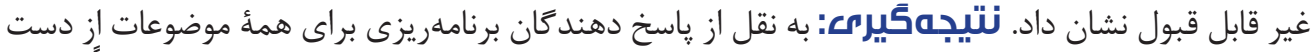

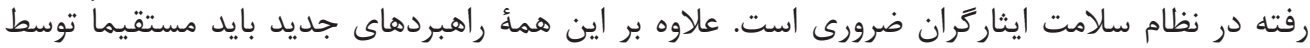
سياست نظام سلامت ايثار كران مديريت شوند.

كليد وازهها:

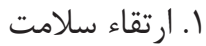
ب إيثار

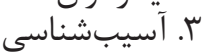

" : نويسنده مسئول: محسن ميرانصارى آدرس الكترونيكى: mmiransari@yahoo.com 


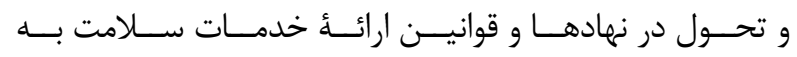

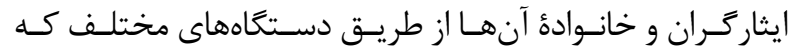

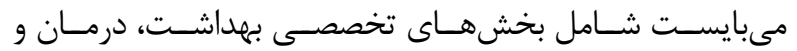

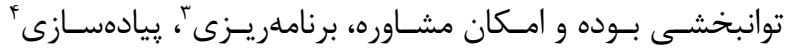

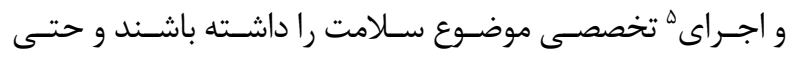

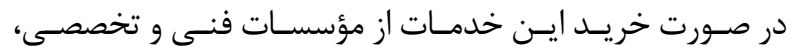

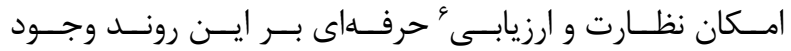

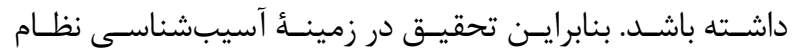

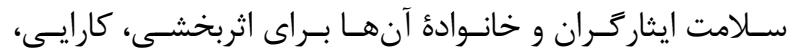

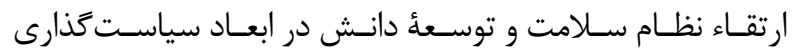

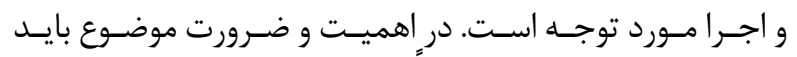

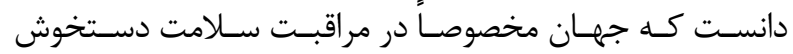

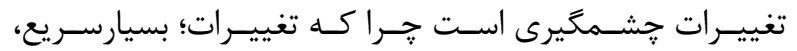

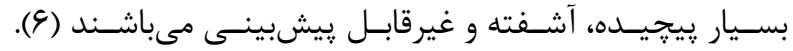

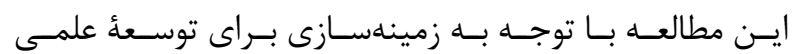

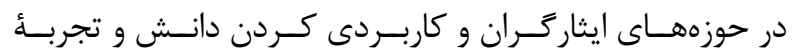

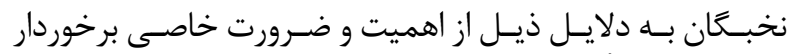

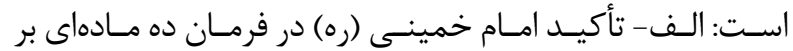

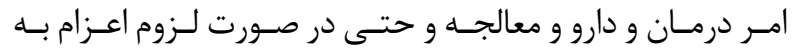

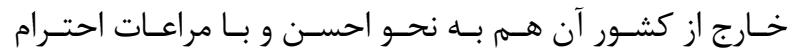

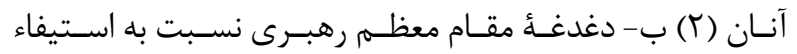

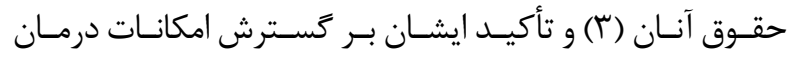

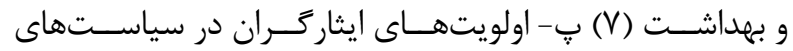

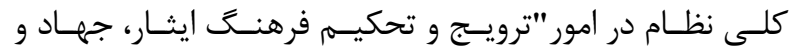

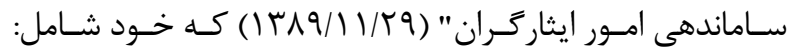

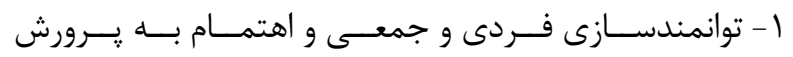

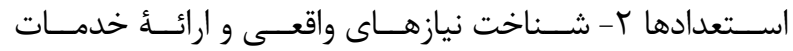

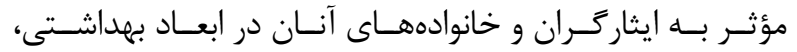

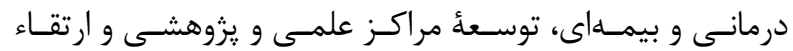

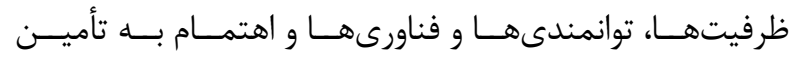

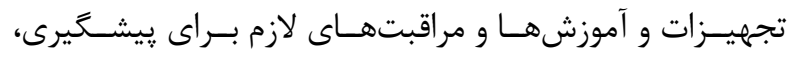

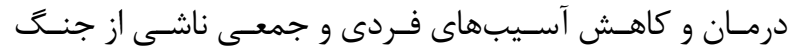

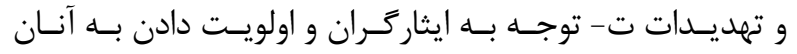

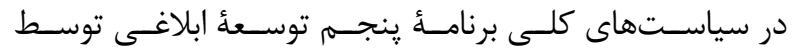

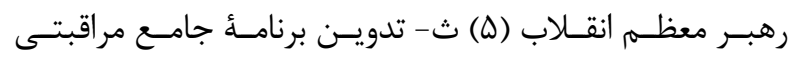

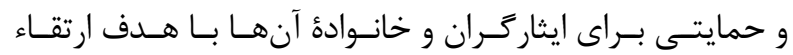

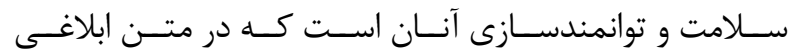

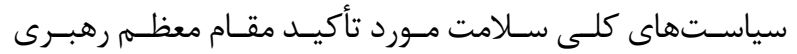

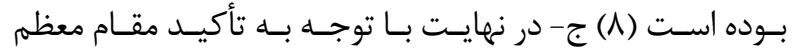

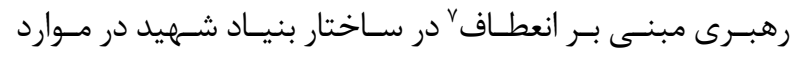

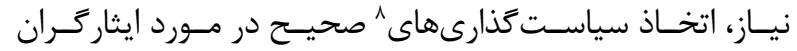

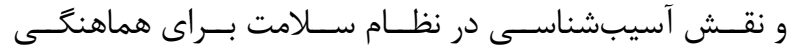

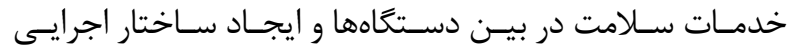

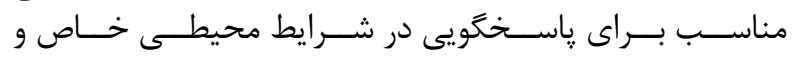

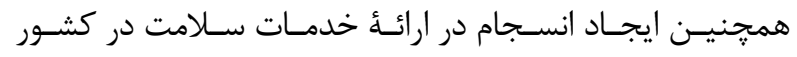

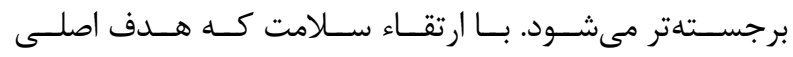

${ }^{1}$ Health system

${ }^{2}$ Veteran

${ }^{3}$ Planning

Implementation

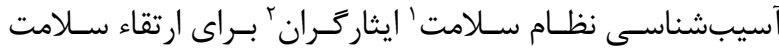

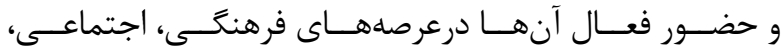

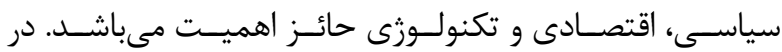

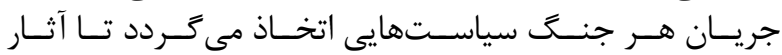

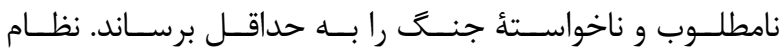

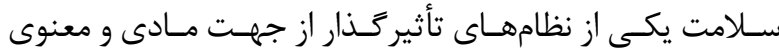

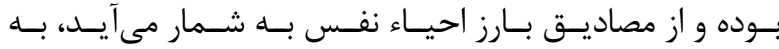

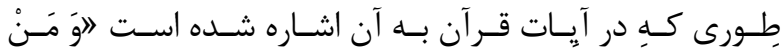

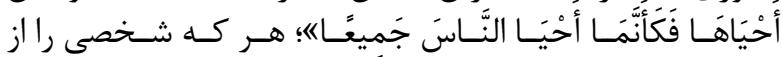

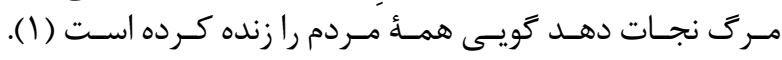

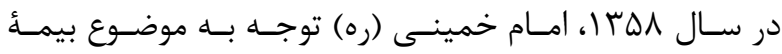

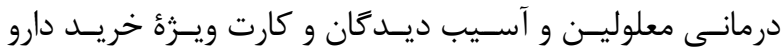

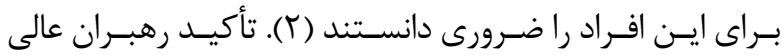

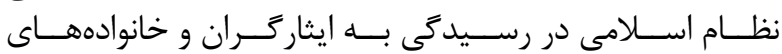

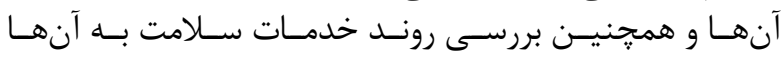

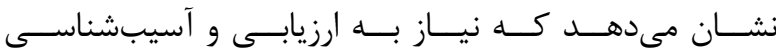

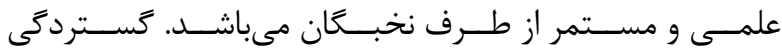

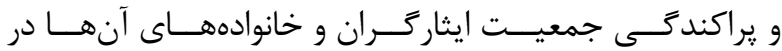

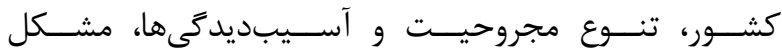

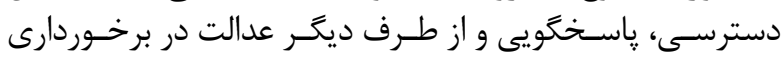

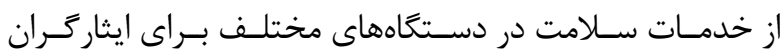

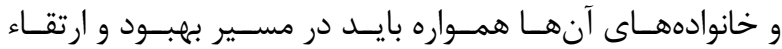

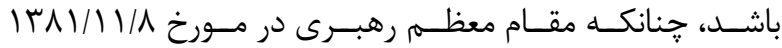

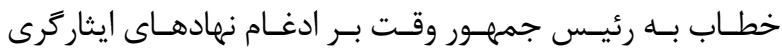

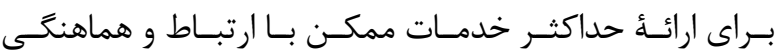

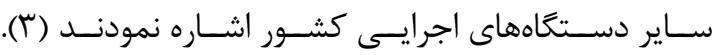

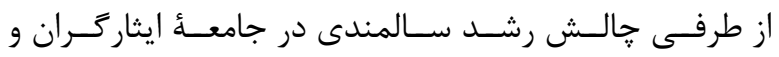

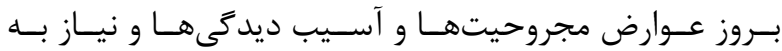

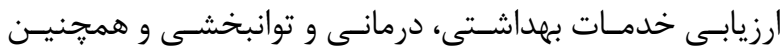

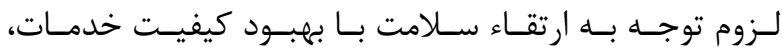

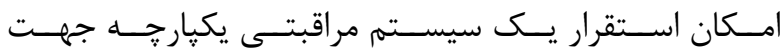

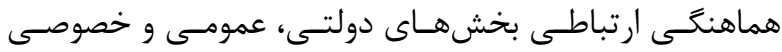

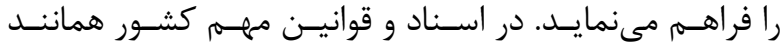

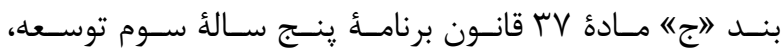

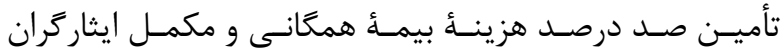

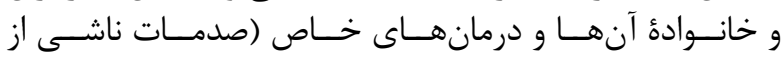

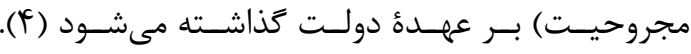

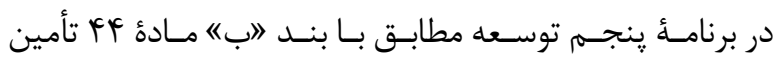

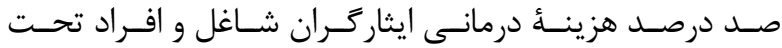

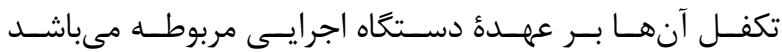

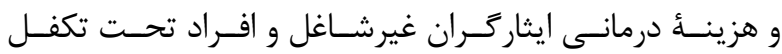

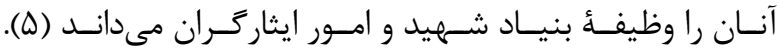

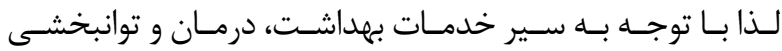

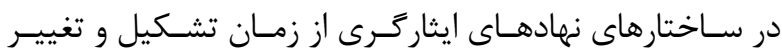

${ }^{5}$ Execution

${ }^{6}$ Evaluation

${ }^{7}$ Flexibility

${ }^{8}$ Policy 


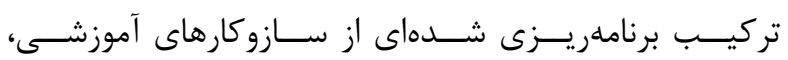

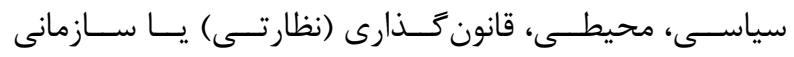

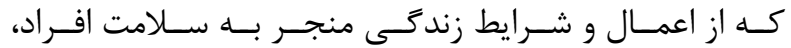

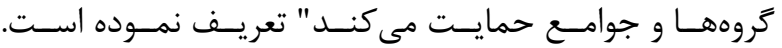

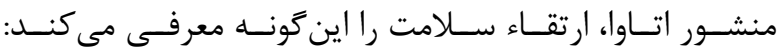

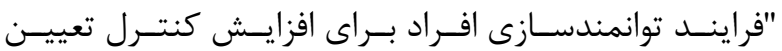

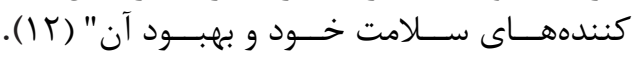
نظام سالامت

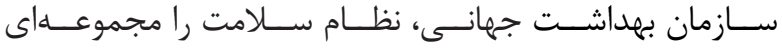

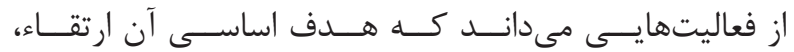

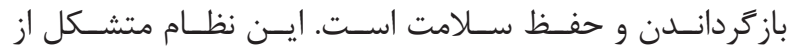

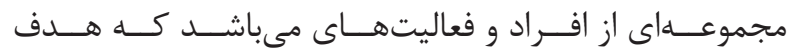

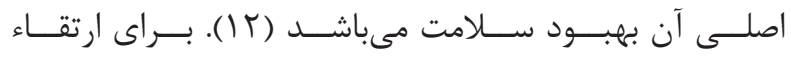

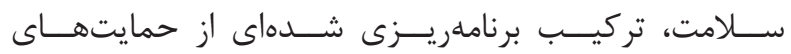

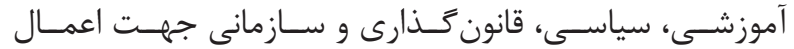

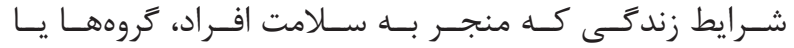

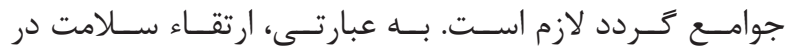

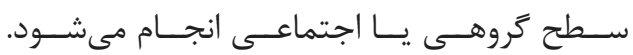
اجزاء ساختارى سيستمهاى سلامت

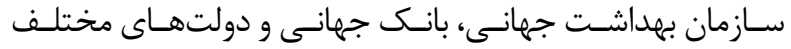

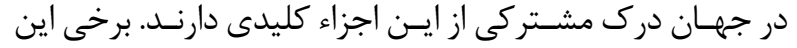

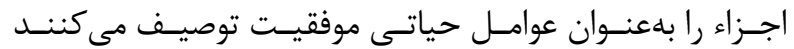

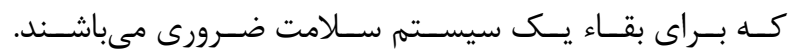

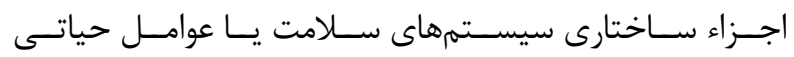

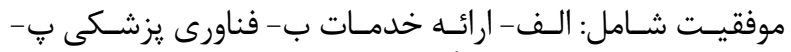

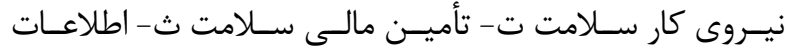

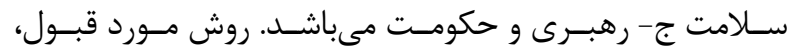

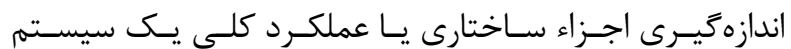

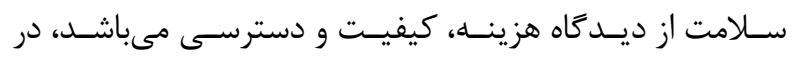

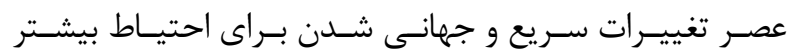

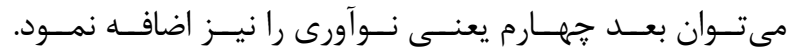

وظايف دولتها در بخش سلامت

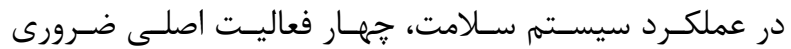

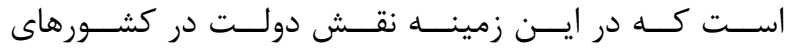

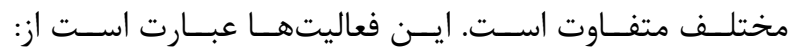

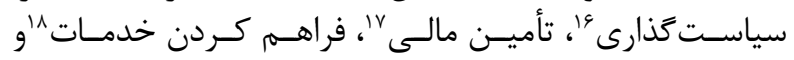

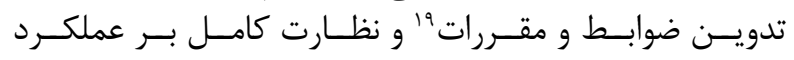

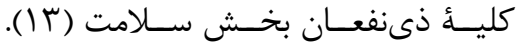

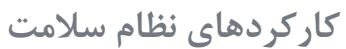

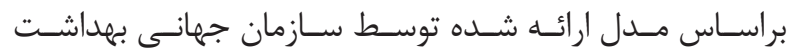

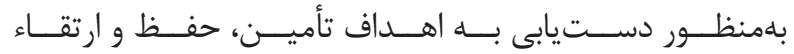

\section{${ }^{9}$ Aging}

${ }^{10}$ Challenge

${ }^{11}$ Social functions

${ }^{12}$ Process

${ }^{13}$ Analysis of the environmental

${ }^{14}$ Effective

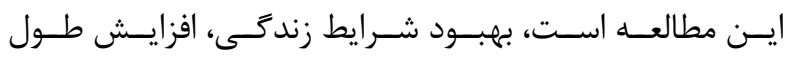

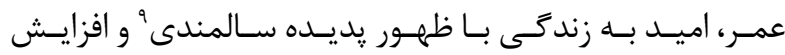

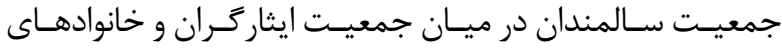

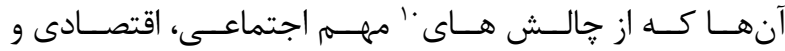

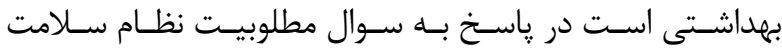

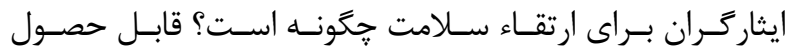

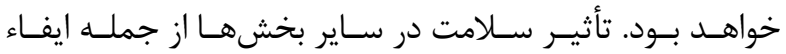

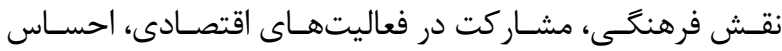

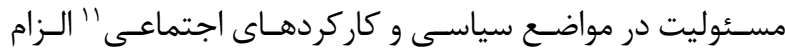

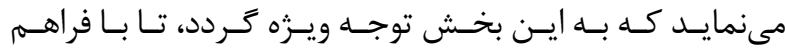

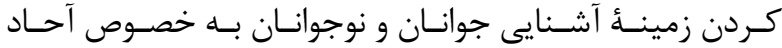

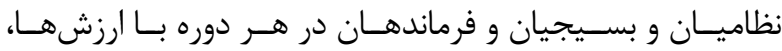

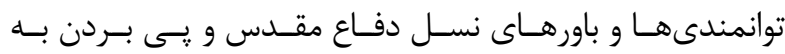

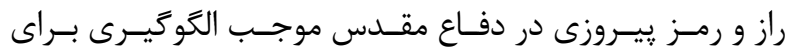

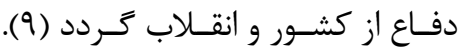

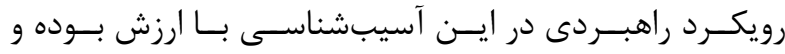

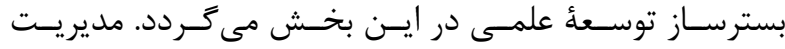

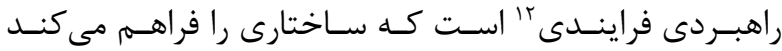

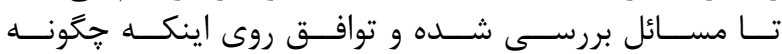

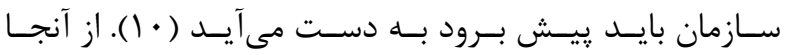

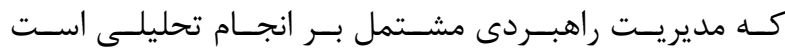

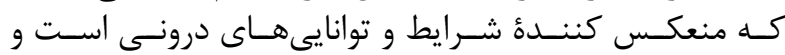

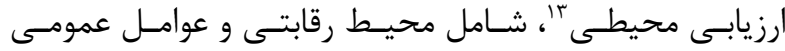

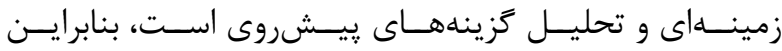

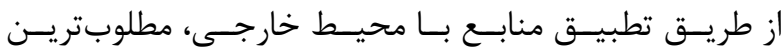

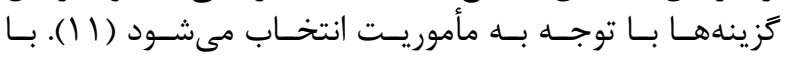

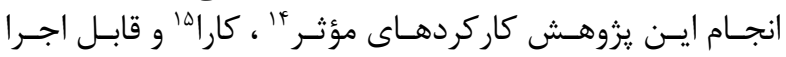

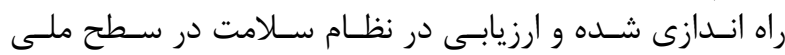

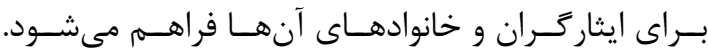

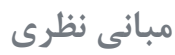

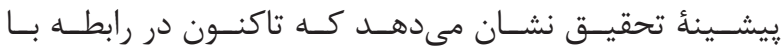

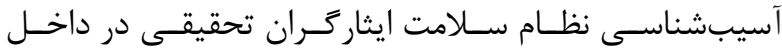

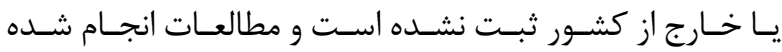

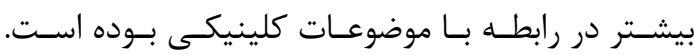

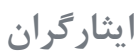

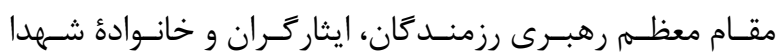

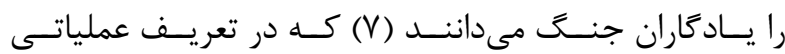

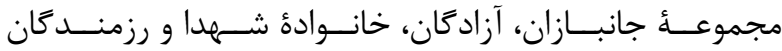

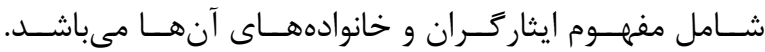

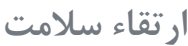

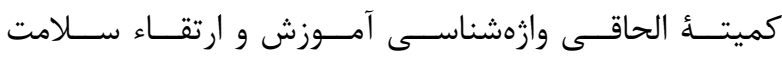

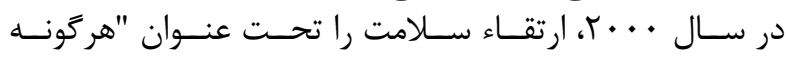
${ }^{15}$ Efficient

${ }^{16}$ Policy formation

${ }^{17}$ Financing

${ }^{18}$ Service provision

${ }^{19}$ Regulation 
قانون اساسنامه بنياد شهيد و امور ايثاركران

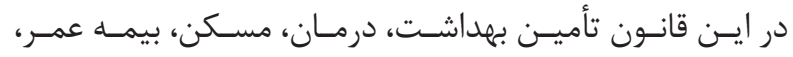

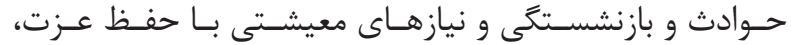

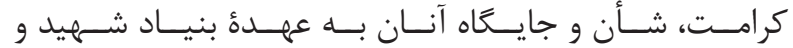

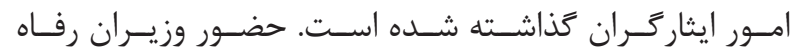

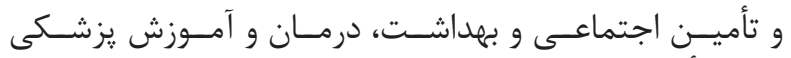

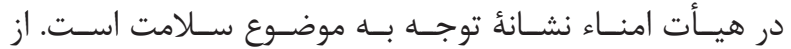

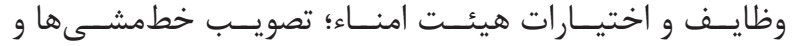

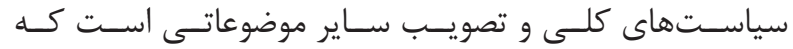

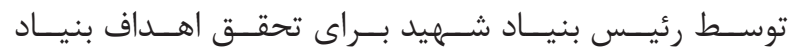

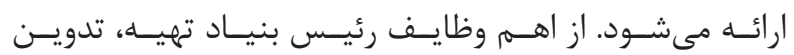

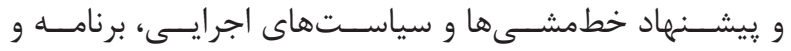

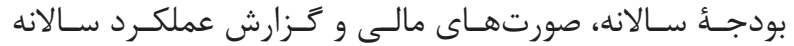

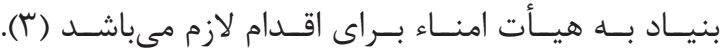

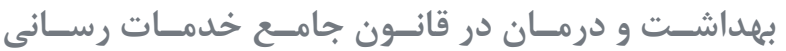
بــه ايثارتـــــان

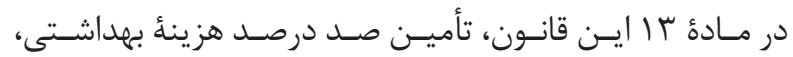

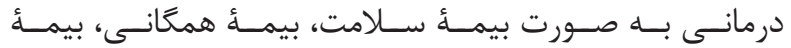

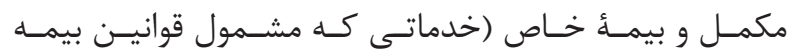

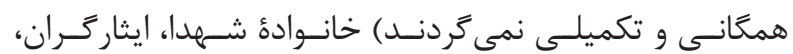

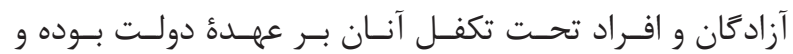

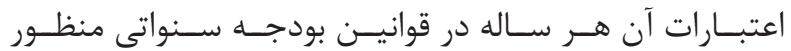

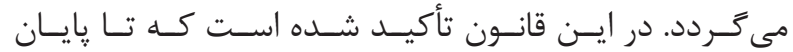

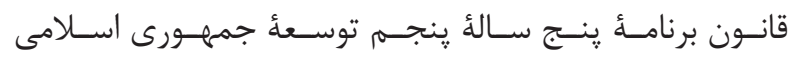

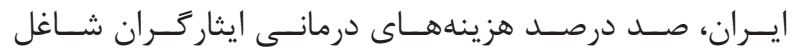

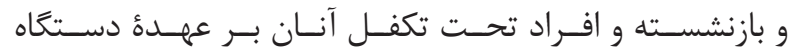

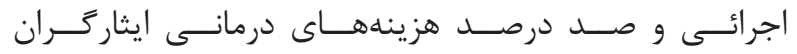

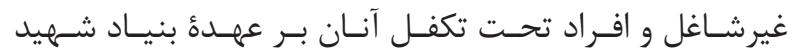

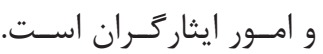

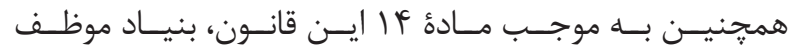

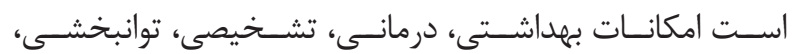

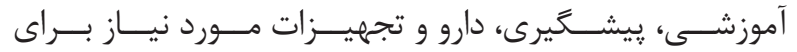

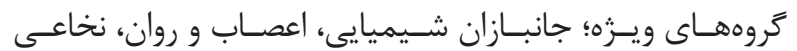

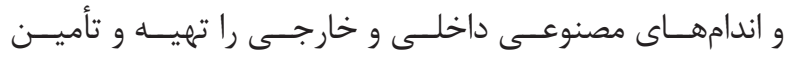

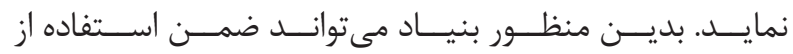

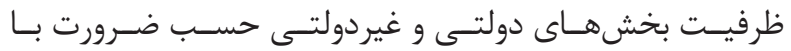

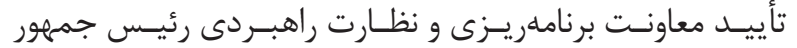

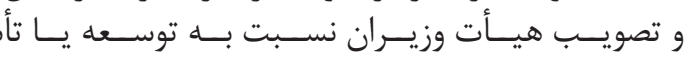

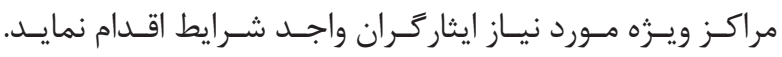

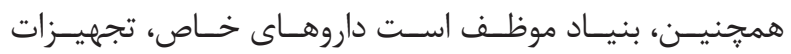

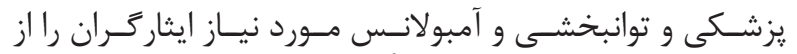

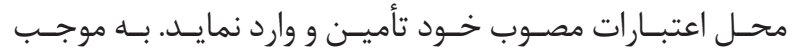

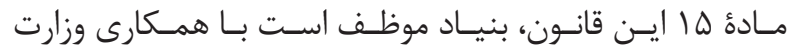

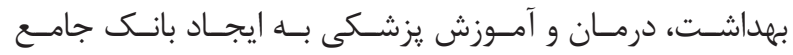

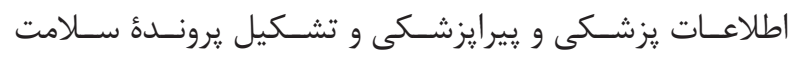

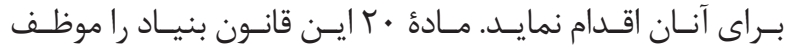

${ }^{20}$ Resource generation

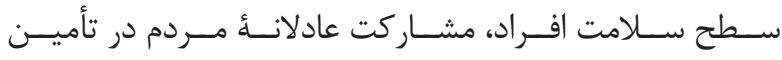

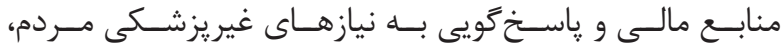

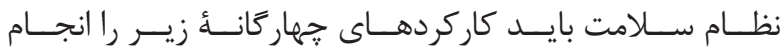

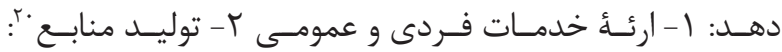

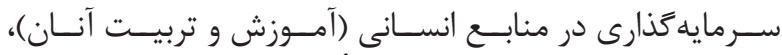

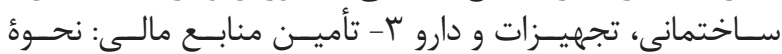

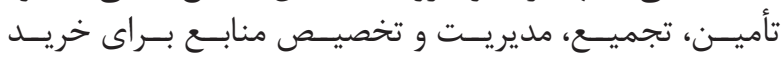

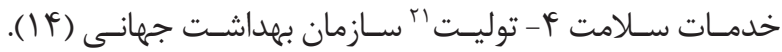

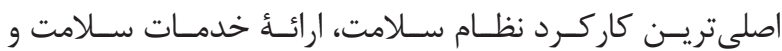

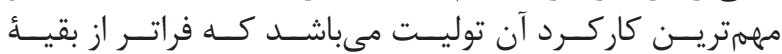

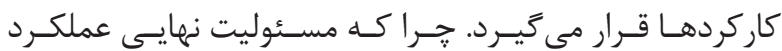

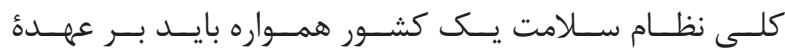

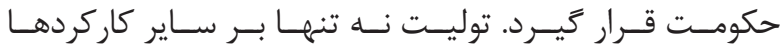

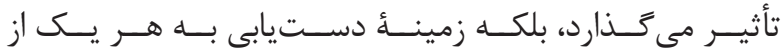

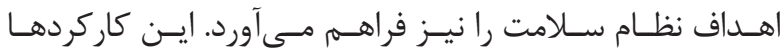

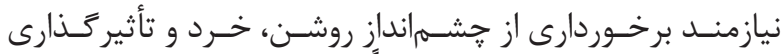

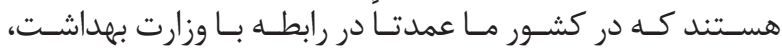

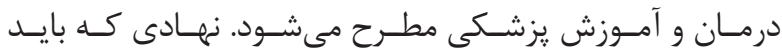

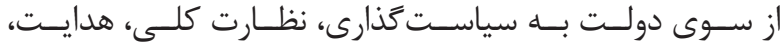

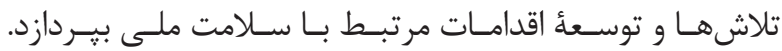

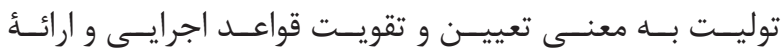

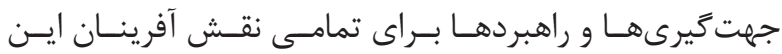

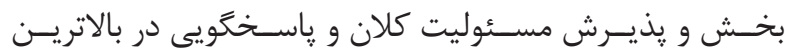

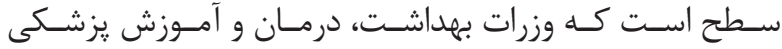

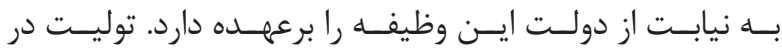

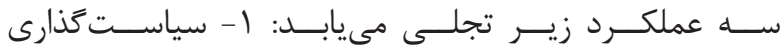

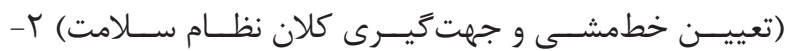

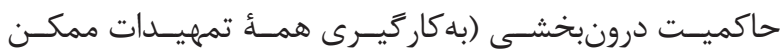

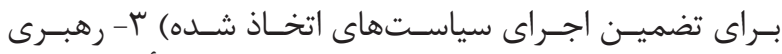

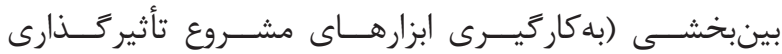

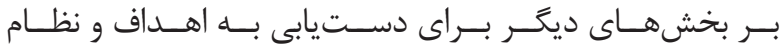

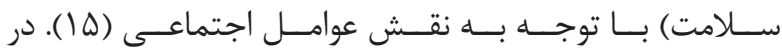

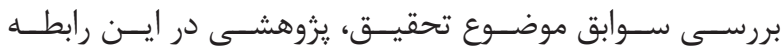

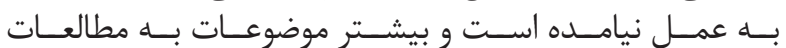

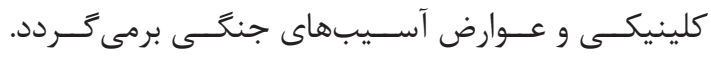
هرم سلامت ايثاركران

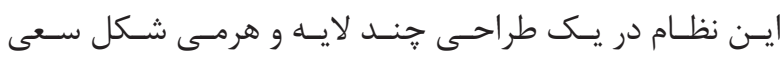

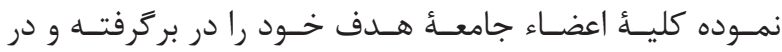

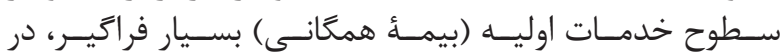

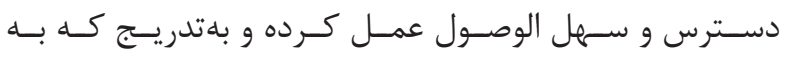

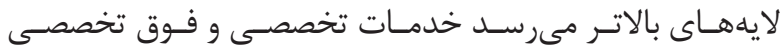

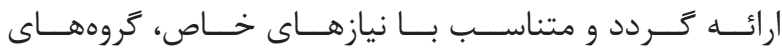

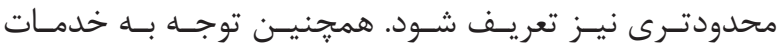

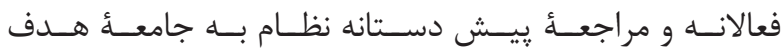

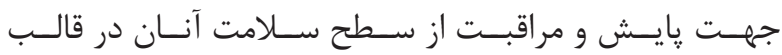

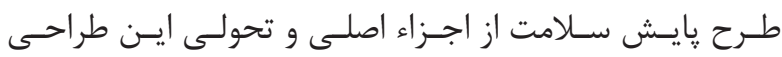
بـوده اسـت (19). 
سياستهاى كلى سلامت

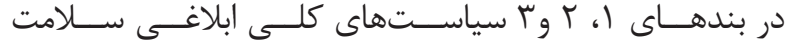

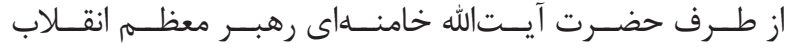

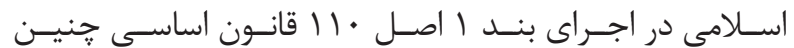

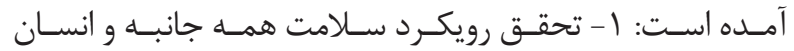

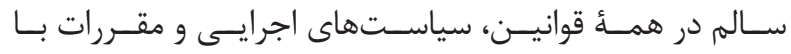

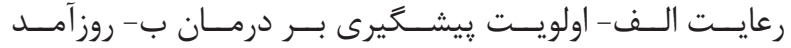

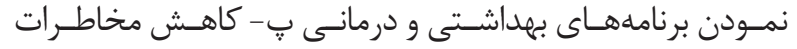

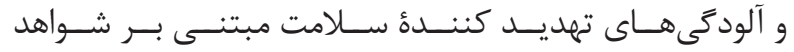

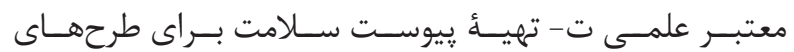

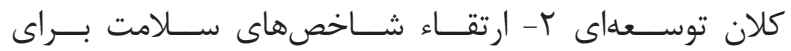

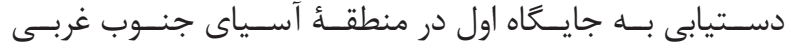

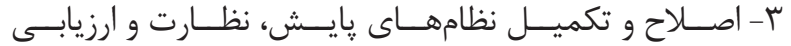

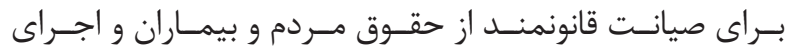

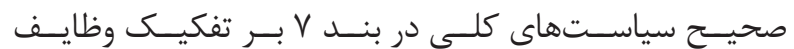

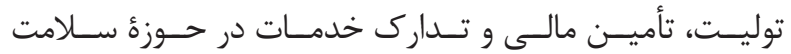

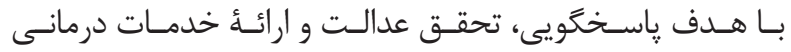

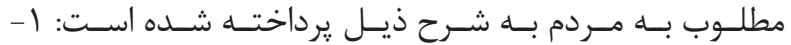

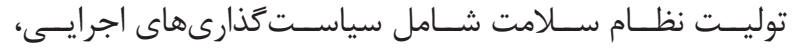

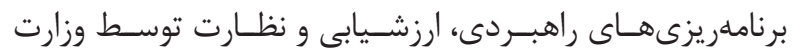

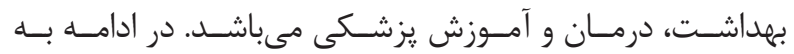

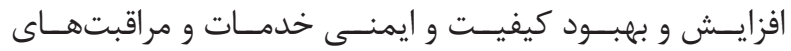

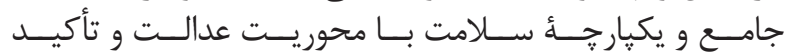

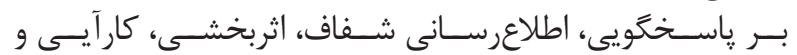

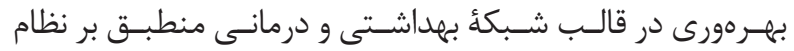

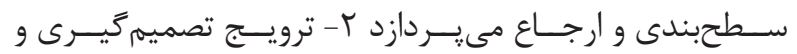

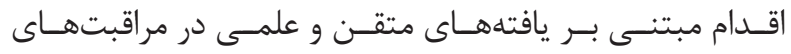

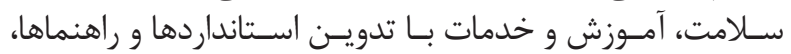

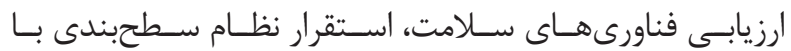

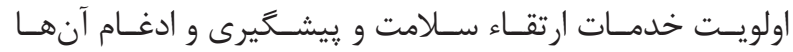

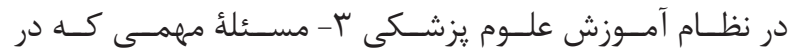

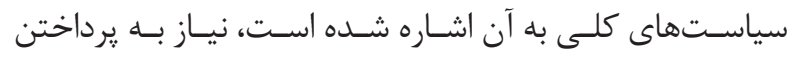

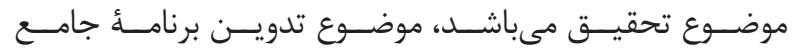

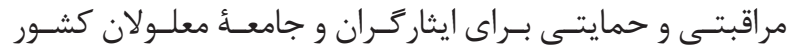

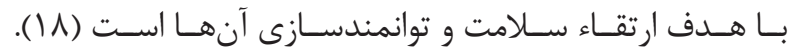

$$
\text { رويكرد راهبردى }
$$

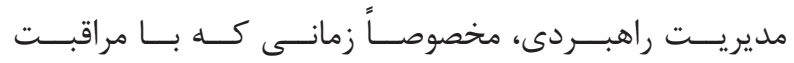

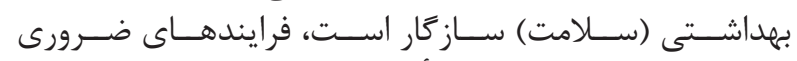

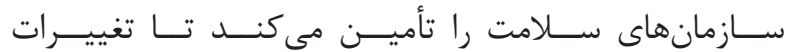

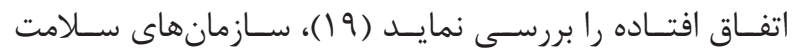

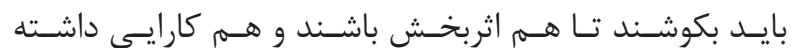

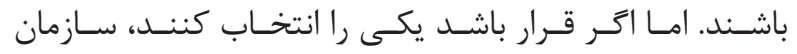

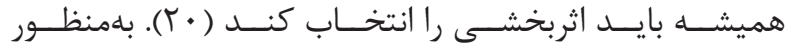

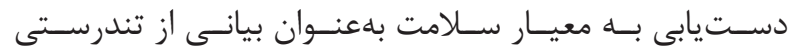

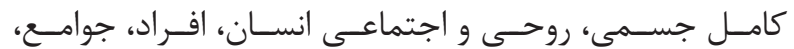

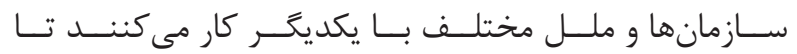

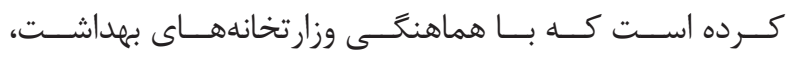

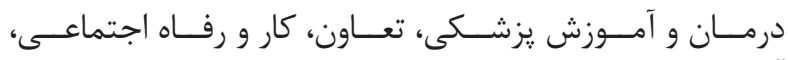

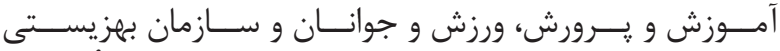

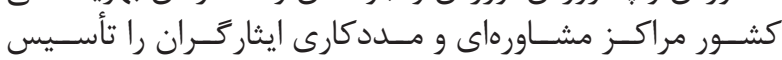

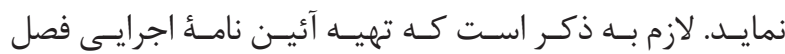

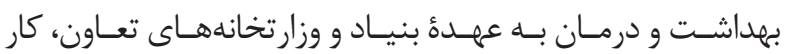

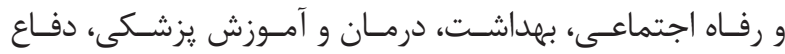

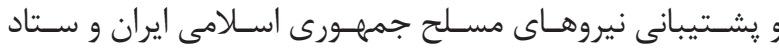

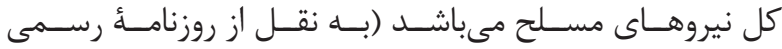

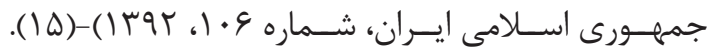
سياســتهاى كلــى نظــام در امــور ترويـــج و تحكيــم

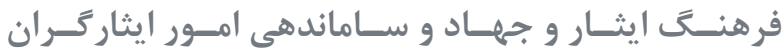
رهبـر انقـلاب اسـلامى سياسـتهاى كلـى نظـام در امـور ترويج

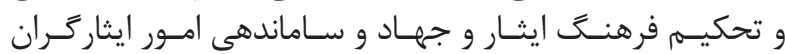

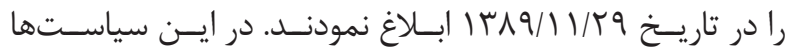

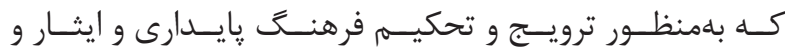

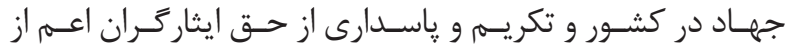

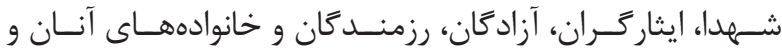

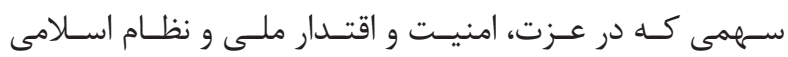

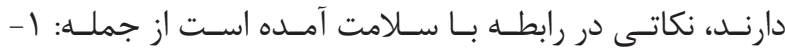

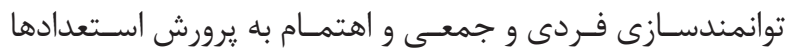

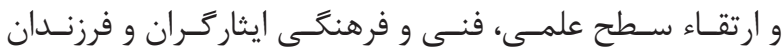

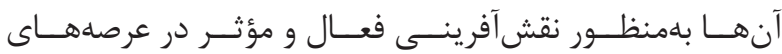

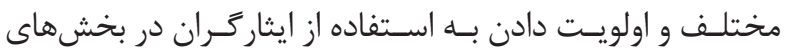

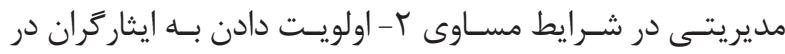

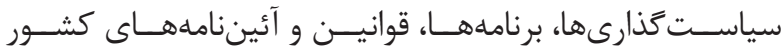

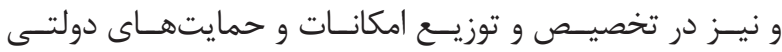

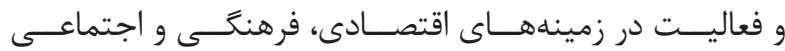

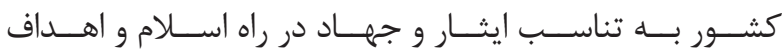

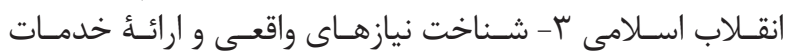

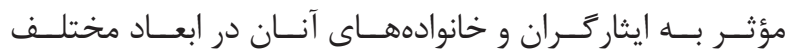

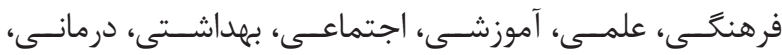

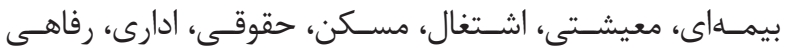

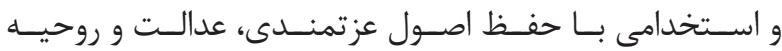

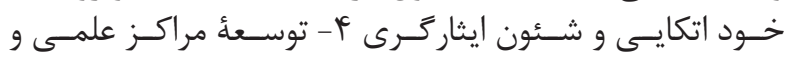

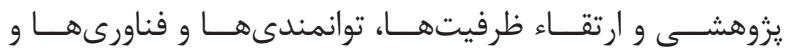

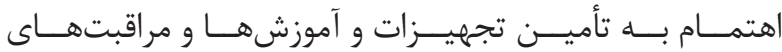

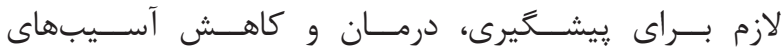

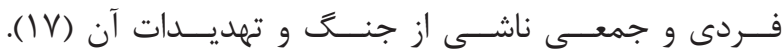

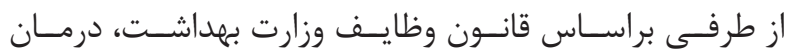

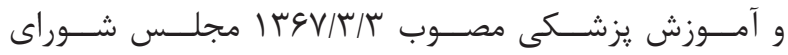

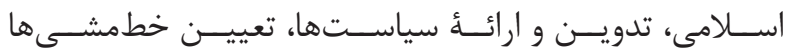

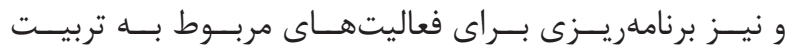

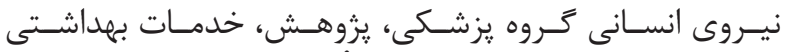

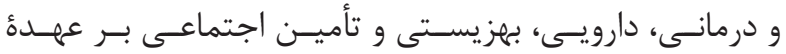

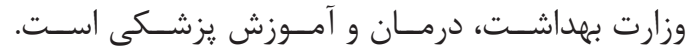




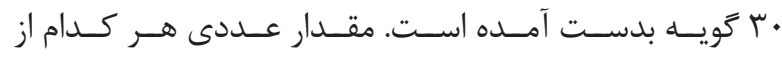

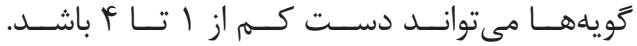
روايى و پإيايى پرسشنامه

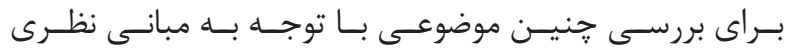

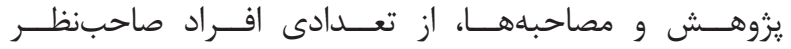

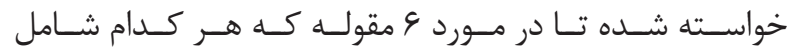

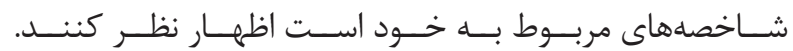

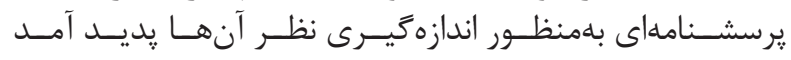

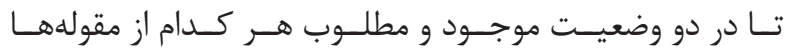

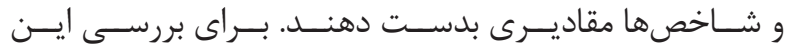

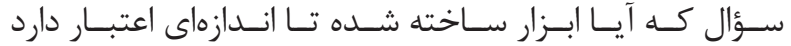

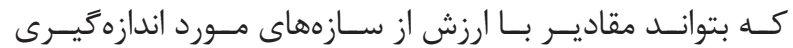

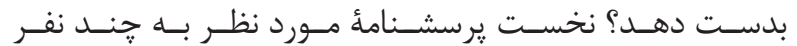

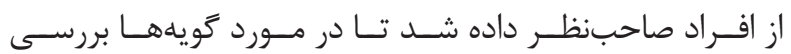

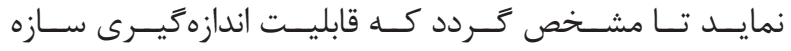

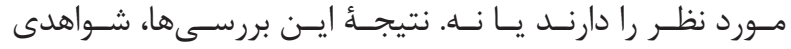

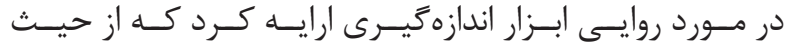

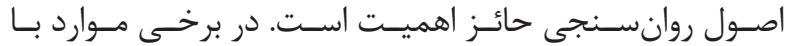

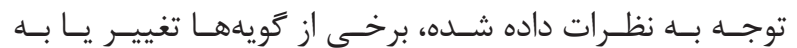

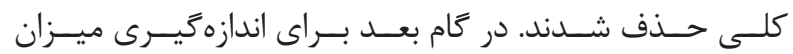

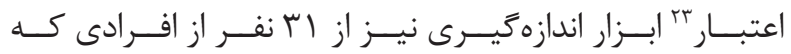

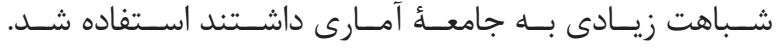

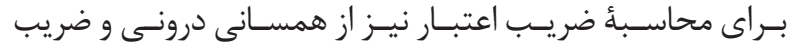

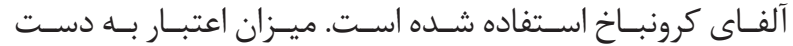

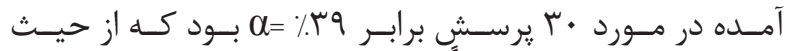

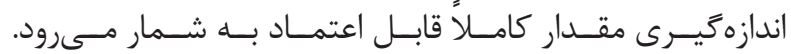

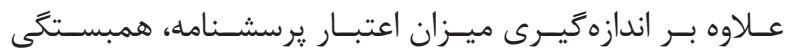

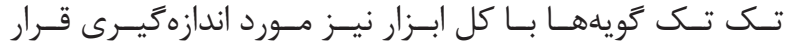

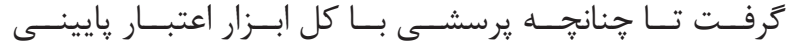

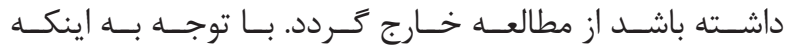

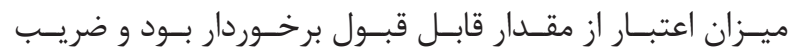

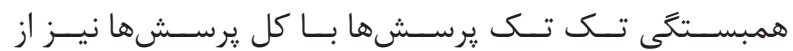

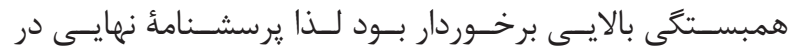

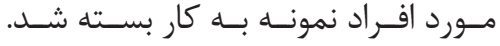

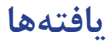
توصيف آمارى دادهها

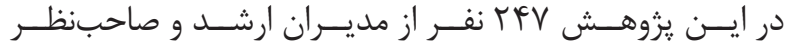

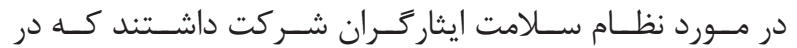

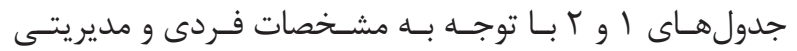

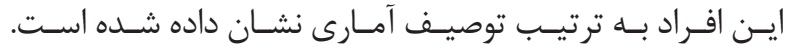

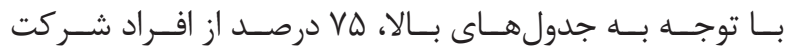

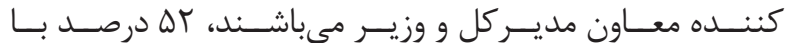

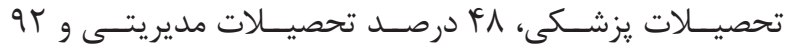

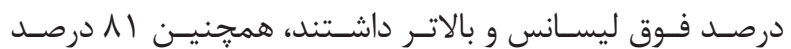

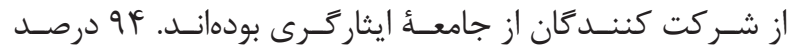

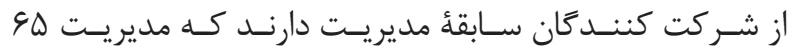

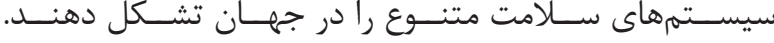

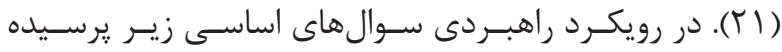

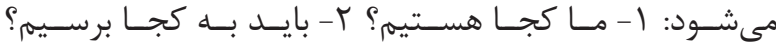

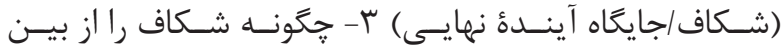

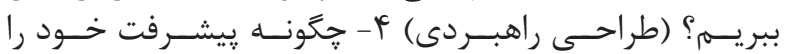

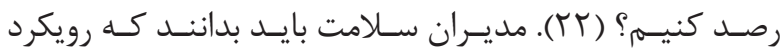

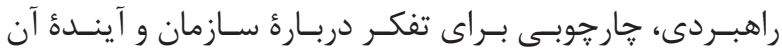

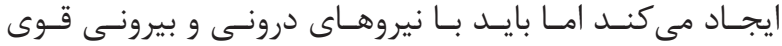

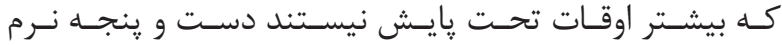

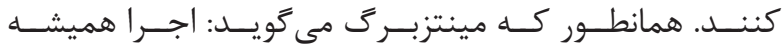

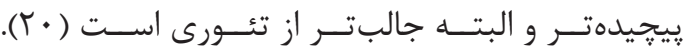

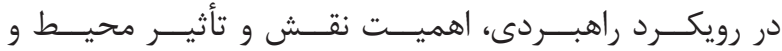

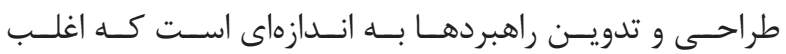

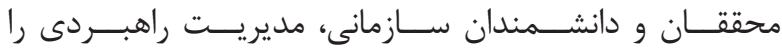

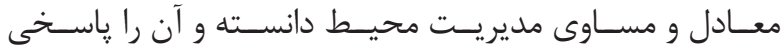

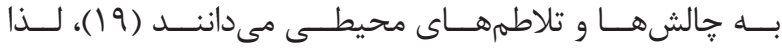

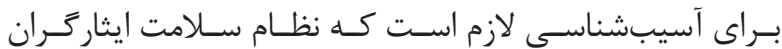

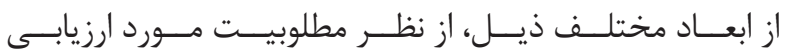

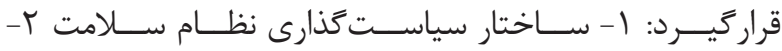

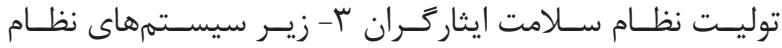

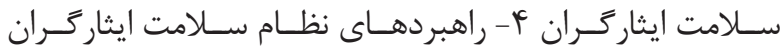

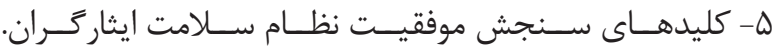

$$
\text { روش شناسى تحقيق }
$$

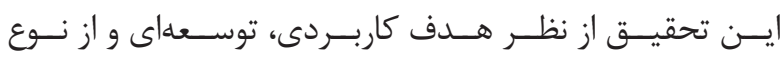

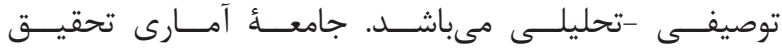

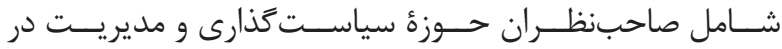

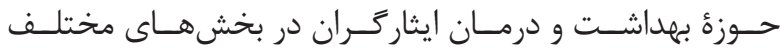

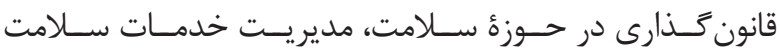

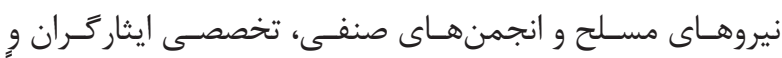

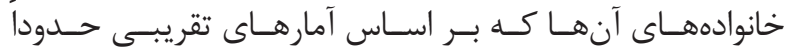

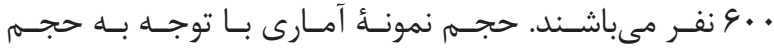

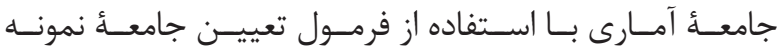

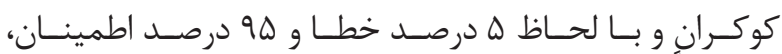

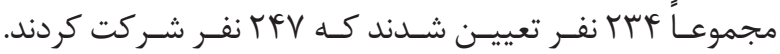

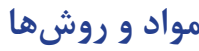
كرد آورى اطلاعات و تحليل دادهها

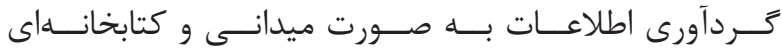

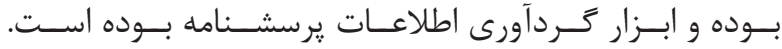

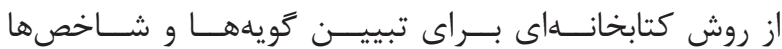

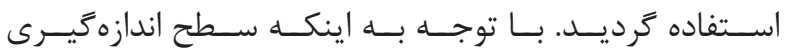

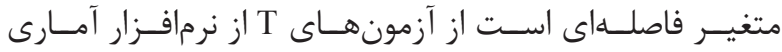

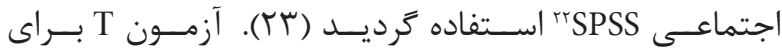

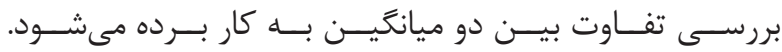

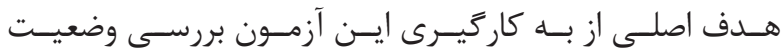

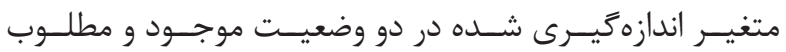

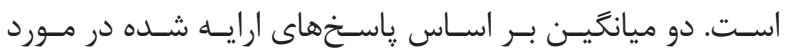


جدول ا- مشخصات فردى جامعهُ آمارى.

\begin{tabular}{|c|c|c|c|c|c|c|c|c|c|}
\hline \multicolumn{2}{|c|}{ مقطع تحصيلى } & \multicolumn{2}{|c|}{ رشتهٔ تحصيلى } & \multicolumn{2}{|c|}{ ايثاركرى } & \multicolumn{2}{|c|}{ سن } & \multicolumn{2}{|c|}{ جنس } \\
\hline فوق ليسانس & دكترا & مديريت & يزشكى & غير ايثاركر & ايثارگر & زير ه广 & بالاى هr & زن & 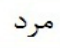 \\
\hline$\%$ & $\%$. & $\%$ \&A & $\% \Delta T$ & $\% 19$ & $\% 11$ & $\% \Delta$ & $\% 90$ & $\%$ & $\% 9 v$ \\
\hline
\end{tabular}

جدول r- مشخصات مديريتى جامعلة آمارى.

\begin{tabular}{|c|c|c|c|c|c|c|}
\hline \multicolumn{3}{|c|}{ مديريت مرتيط با ايثارتران } & \multicolumn{2}{|c|}{ سمت } & \multicolumn{2}{|c|}{ سابقة مديريت } \\
\hline فاقد سابقةُ مديريت & غيرمرتبط با ايثاركران & مرتبط با ايثاركران & هايينتر از مديركل & مديركل و بالاتر & فاقد سابقه & داراى سابقه \\
\hline$\%$ & $\%$. & $\% .90$ & $\%$ ro & $\% \vee \Delta$ & $\% .9$ & $\% .9 f$ \\
\hline
\end{tabular}

جدول r- مطلوبيت ساختار سياست كذارى نظام سلامت ايثاركران از حيث معنى ارىى.

\begin{tabular}{|c|c|c|c|c|}
\hline $\mathbf{T}$ & درجئ آزادى & معنى دارى & اختلاف ميانغينها & شاخصها \\
\hline$-I V / \Delta \Delta \Lambda$ & $F \wedge \Lambda$ & $\cdots 1$ & $-1 / \cdot \Delta V$ & رئيس جمهور و هيأت دولت \\
\hline$-1 V / 1 \times 4$ & $4 q$. & $\because \cdots$ & $-\cdot / 94 V$ & مجلس شوراى اسلامى \\
\hline$-I V / I T V$ & $4 \wedge 9$ & $\because \cdots$ & $-1 / 1 / 9$ & هيأت امناء بنياد شهيد و امور \\
\hline$-10 / 9 Y \mid$ & $4 \wedge 9$ & $\because \cdots$ & $-1 / 11 r$ & ستاد كل نيروهاى مسلح \\
\hline $\begin{array}{l}-1 f / \cdot \mid \cdot . \\
0\end{array}$ & \&VA & $\ldots$ & $-1 / \cdot \wedge \Lambda$ & مجمع تشخيص مصلحت نظام \\
\hline
\end{tabular}

ب- مقولـهُ مطلوبيـت توليـت نظـام سـلامت ايثارگــــان، كــهـ

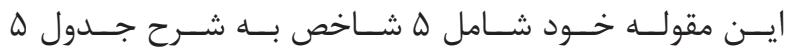

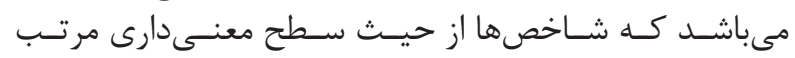

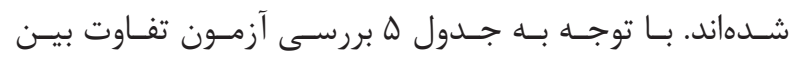

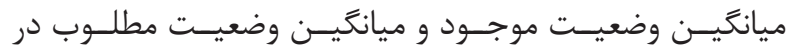

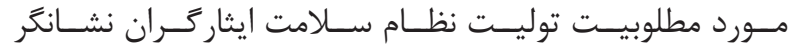

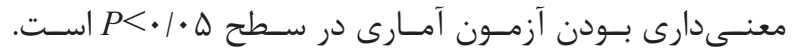

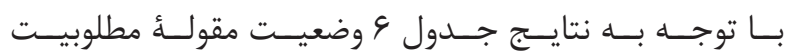

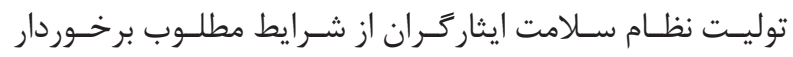

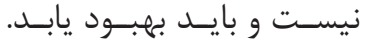

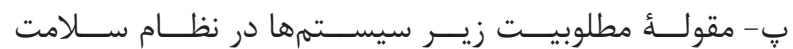

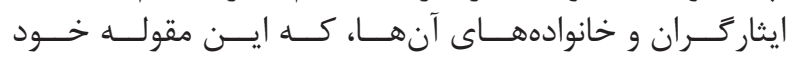

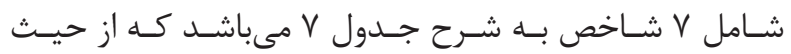

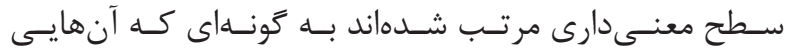

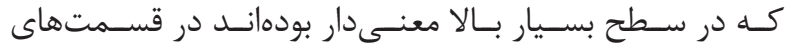

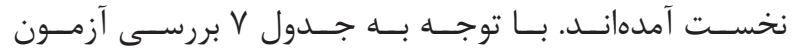

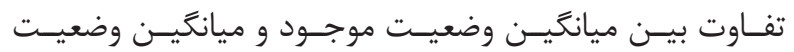

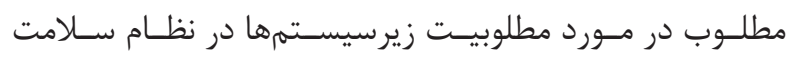

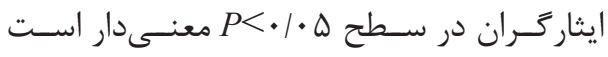

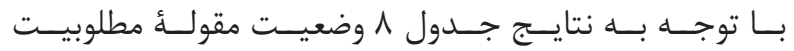

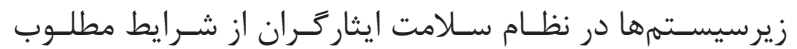

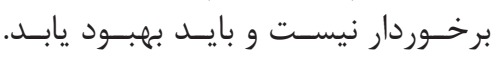

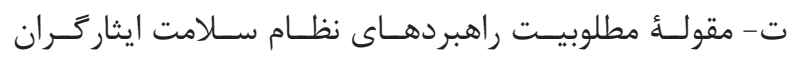

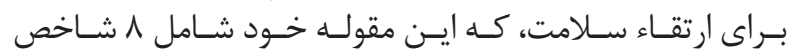

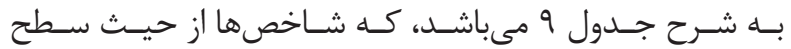

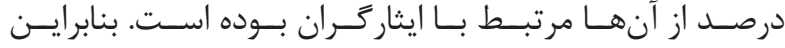

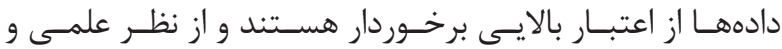

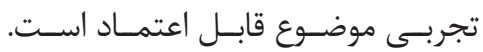
تحليل آمارى دادهها

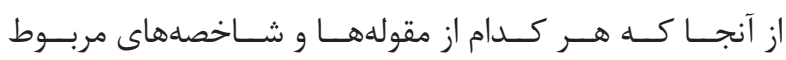

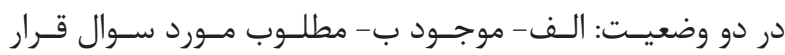

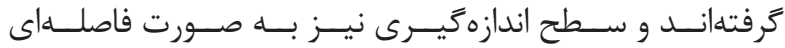

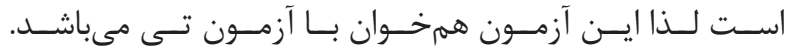

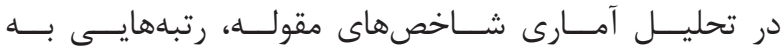

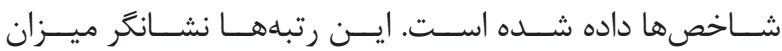

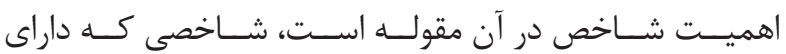

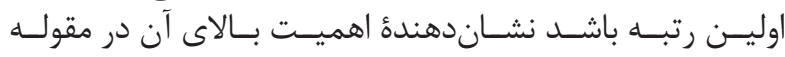
مى باشـــد.

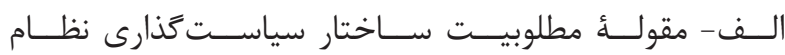

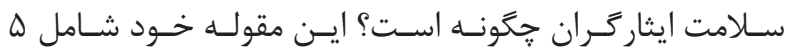

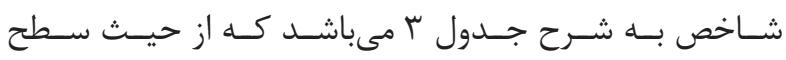

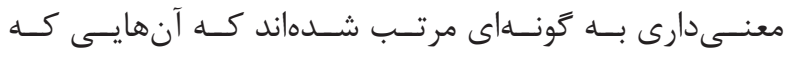

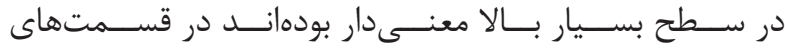

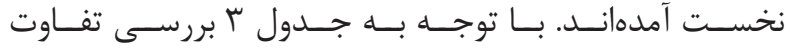

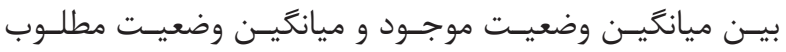

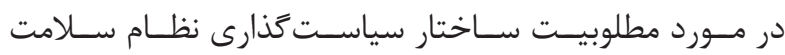

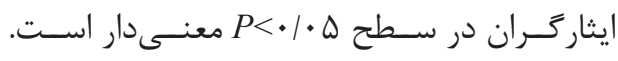

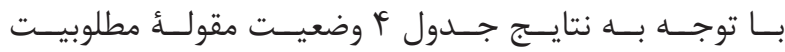

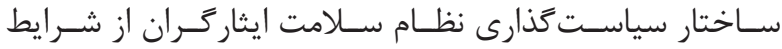

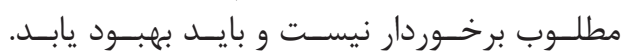




\begin{tabular}{|c|c|c|c|c|c|c|}
\hline $\mathrm{N}$ & ميانگين & انحراف استاندارد & $\mathrm{T}$ & $\mathrm{df}$ & معنى دارى & وضعيت \\
\hline rrv & $\mid T / T F \cdot D$ & T/ATEY. & - & - & - & موجود \\
\hline aq & $18 / 9990$ & T/১TVA১ & $r T / \cdot \Delta r$ & Fre & معنى دار & مطلوب \\
\hline
\end{tabular}

جدول ه- مطلوبيت توليت نظام سلامت ايثاركران و خانوادهاى آنها از حيث معنى دارى.

\begin{tabular}{|c|c|c|c|c|}
\hline $\mathrm{T}$ & درجه آزادى & معنى دارى & اختلاف ميانكينها & شاخصها \\
\hline$-T \omega / 1 T^{\prime}$ & pq. & $\cdot / \cdots$ & $-1 / 411$ & وزارت بهداشت، درمان و آموزش \\
\hline$-19 / 94$. & $\uparrow \wedge \wedge$ & $\cdot / \cdots$ & $-1 / k 4$. & انجمنهاى صنفى \\
\hline$-\mid 1 / V 10$ & 4人9 & $\cdot / \cdots$ & - - & وزارت تعاون، كار و رفاه اجتماعى \\
\hline$-\mid N \cdot F \lambda$ & $4 \wedge 9$ & $\cdot / \cdots$ & $-1 / r \Delta 9$ & وزارت دفاع و يشتيبانى نيروهاى \\
\hline$-1 \pi / 9 \cdot \Delta$ & 491 & $\cdot \cdots$ & $-\cdot / \Lambda \cdot \Delta$ & بنياد شهيد و امور ايثاركران \\
\hline
\end{tabular}

جدول 9- آزمون آمارى مطلوبيت توليت نظام سلامت ايثار كران و خانوادهاى آنها.

\begin{tabular}{|c|c|c|c|c|c|c|}
\hline $\mathrm{N}$ & ميانگين & انحراف استاندارد & $\mathrm{T}$ & df & معنى دارى & وضعيت \\
\hline TFT & $1 \cdot / 0 T \wedge 9$ & $r / G \cdot V T \Lambda$ & - & - & - & موجود \\
\hline$r f$ & 19/945V & T/DDTTK & $r r / \cdot \Delta r$ & Fへl & معنسى دار & مطلوب \\
\hline
\end{tabular}

جدول V - مطلوبيت زيرسيستمها در نظام سلامت ايثاركران از حيث معنى دارى.

\begin{tabular}{|c|c|c|c|c|}
\hline $\mathrm{T}$ & درجة آزادى & منيى دارى & اختاف ميانكينهـا & شاخصرها \\
\hline$-r r / / 19$ & fq. & $\cdot / \cdots$ & $-1 / 191$ & تحقيق و بروهش \\
\hline$-r t / V q$ & fAV & $\cdot 1 \cdots$ & -I/ATS & ارزيابى و ارتقاء عملكرد \\
\hline -tq/4q4 & $4 \wedge 9$ & $\cdot / \cdots$ & $-1 / \Delta \wedge 9$ & بايش سلامت \\
\hline -TA/VET & fq. & $\cdot 1 \cdots$ & $-1 / 90$. & تأمين و آموزش منابع انسانى \\
\hline -TVITET & 491 & $\cdot / \cdots$ & $-1 / 911$ & توسعة اطلاعات و فنبورى بزشكى \\
\hline -th/IVt & fᄉ9 & $\cdot 1 \cdots$ & $-1 / f t r$ & ارائئ خدمات سلامت \\
\hline -TT/ITT & 491 & $\cdot 1 \cdots$ & $-1 / T \cdot T$ & تأمين منابع مالى و يشتيبنى درمان \\
\hline
\end{tabular}

جدول ^- آزمون آمارى مطلوبيت زيرسيستمها در نظام سلامت ايثاركران و خانوادهاى آنها.

\begin{tabular}{|c|c|c|c|c|c|c|}
\hline $\mathrm{N}$ & ميانگين & انحر اف استاندارد & $\mathrm{T}$ & df & معنى دارى & وضعيت \\
\hline TFT & $\mid F / \Delta V F F$ & $\Gamma / \Delta \mid r \Delta \Delta$ & - & - & - & موجود \\
\hline TFT & 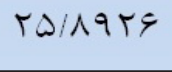 & $r / 11199$ & & FAT & & مطلوب \\
\hline
\end{tabular}

جدول 9- مطلوبيت راهبردهاى نظام سلامت ايثاركران از حيث معنى دارى.

\begin{tabular}{|c|c|c|c|c|}
\hline $\mathrm{T}$ & درجه آزادى & معنى دارى & اختاف ميانكينها & شاخصها \\
\hline$-r T / T \Delta V$ & $4 q 1$ & $\cdot / \cdots$ & $-1 / 919$ & آموزش بهداشت و تغذيه \\
\hline$-r / \Delta \Delta \Lambda$ & fqr & $\cdot 1 \cdots$ & $-|/ \vee \wedge|$ & مشاوره و مددكارى \\
\hline - TG/GYF & $4 \wedge 9$ & $\cdot / \cdots$ & $-1 / 959$ & مراقبتهاى بزنكى در مـنزل \\
\hline$-r \Delta / 9+r$ & 4q1 & $\cdot / \cdots$ & $-1 / \Delta F r$ & خدمات سريايى و دندانيزشكى \\
\hline -Yr/aV. & 419 & $\cdot / \cdots$ & $-1 / r V V$ & خدمات توانبخشى \\
\hline -tr/YAY & far & $\cdot \cdots$ & $-1 / 4 V 1$ & تأمين دارو و تجهيزات بزشكى \\
\hline$-r \cdot 1195$ & $4 q$. & $\cdot / \cdots$ & $-1 /|V|$ & خدمات ارتز و بروتز \\
\hline- & - & - & - & خدمات بسترى و جراحى \\
\hline
\end{tabular}




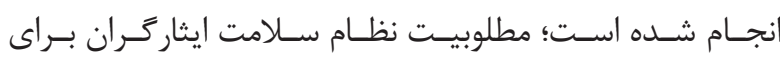

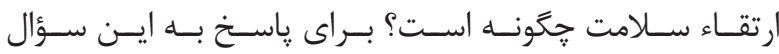

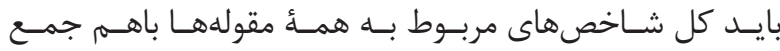

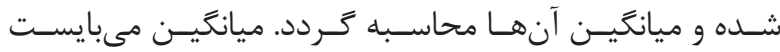

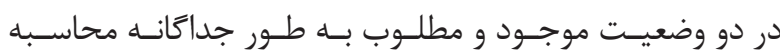

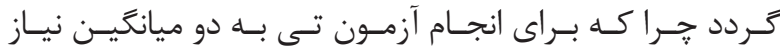

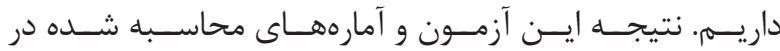

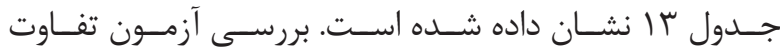

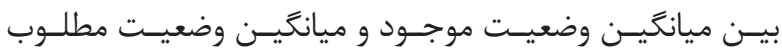

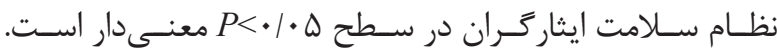

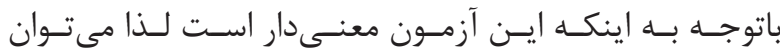

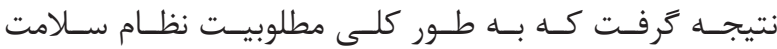

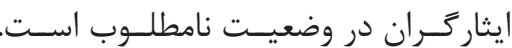

بحث و نتيجه

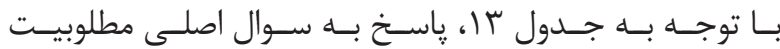

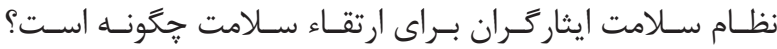

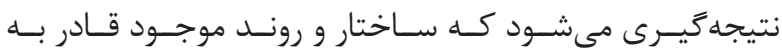

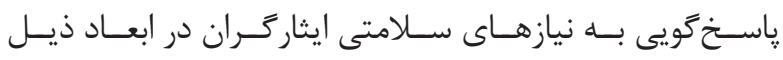

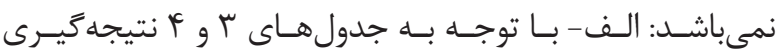

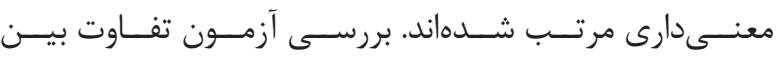

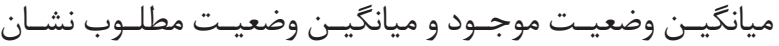

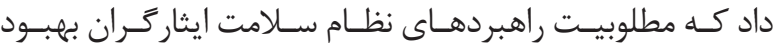

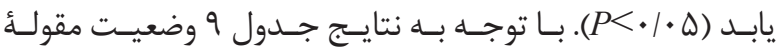

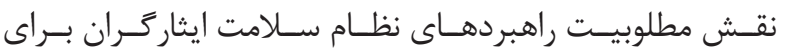

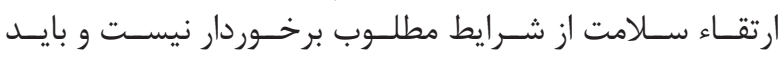
بهبــود يابـد.

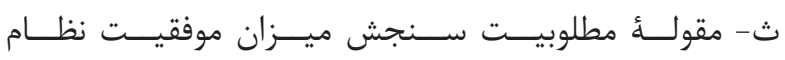

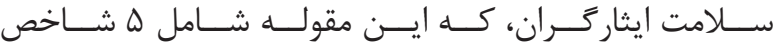

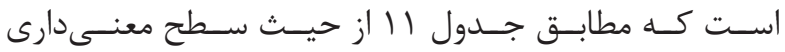

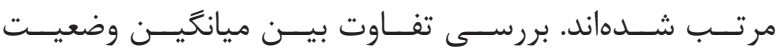

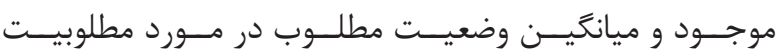

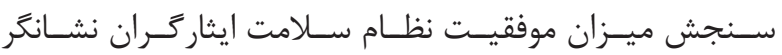

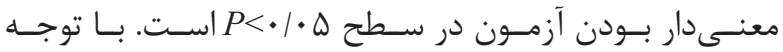

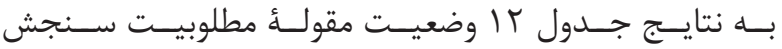

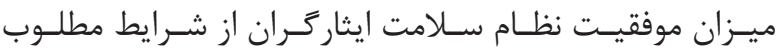
برخــوردار نيسـت و بايــد بهبــود يابــد.

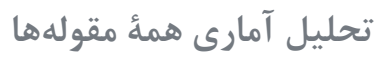

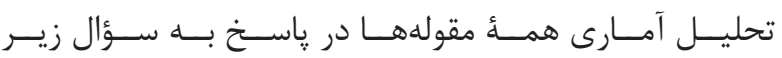

\begin{tabular}{|c|c|c|c|c|c|c|}
\hline $\mathrm{N}$ & ميانگين & انحر اف استاندارد & $\mathrm{T}$ & $\mathrm{df}$ & معنى دارى & وضعيت \\
\hline$T F I$ & IVIVTT. & F/ITUF. & - & - & - & موجود \\
\hline TFT & 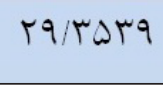 & r/rチq人 & $\mu F / \cdot 10$ & FAT & معنى دار & مطلوب \\
\hline
\end{tabular}

جدول || - مطلوبيت سنجش ميزان موفقيت نظام سلامت ايثاركران از حيث معنى دارى.

\begin{tabular}{|c|c|c|c|c|}
\hline $\mathrm{T}$ & درجئ آزادى & معنى دارى & اختلاف ميانكين & شاخصها \\
\hline$-r T / F V A$ & $4 \wedge 9$ & $\cdot \cdots$ & $-1 / \wedge 91$ & نوآورى \\
\hline$-r r / r q F$ & pq. & $\cdot / \cdots$ & $-1 / V 9$. & اثربخشى \\
\hline$-r \mid / 9 \wedge \mathrm{V}$ & fq. & $\cdot \cdots$ & $-1 / 9 \cdot 9$ & كيفيت \\
\hline$-Y V / \Delta \varphi$. & $F \wedge \Lambda$ & $\cdot / \cdots$ & $-1 / f \Delta r$ & دسترسى \\
\hline$-11 / 4 \Delta 9$ & $4 \wedge 9$ & $\cdot / \cdots$ & $-\cdot / \lambda F t$ & هزينه \\
\hline
\end{tabular}

جدول rا آ آزمون آمارى مطلوبيت سنجش ميزان موفقيت نظام سلامت ايثاركران.

\begin{tabular}{|c|c|c|c|c|c|c|}
\hline $\mathrm{N}$ & ميانگين & انحراف استاندارد & $\mathrm{T}$ & $\mathrm{df}$ & معنى دارى & وضعيت \\
\hline rFT & 1./AFT & r/gVArq & - & - & - & موجود \\
\hline TFA & 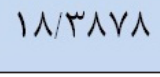 & $r / r \cdot 11 r$ & rV/IFA & $4 \wedge 9$ & معنىى دار & مطلوب \\
\hline
\end{tabular}

جدول سا- آزمون آمارى مطلوبيت نظام سلامت ايثاركران.

\begin{tabular}{|c|c|c|c|c|c|c|}
\hline $\mathrm{N}$ & ميانگين & انحراف استاندارد & $\mathrm{T}$ & df & معنى دار & وضعيت \\
\hline $11 \mathrm{~V}$ & 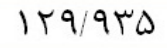 & 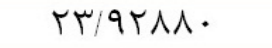 & - & - & - & موجود \\
\hline$r \cdot V$ & TIM/GYV & $r \cdot / 9 \& r F r$ & $\mathrm{rV} / \cdot 11$ & rqr & معنسى دار & مطلوب \\
\hline
\end{tabular}




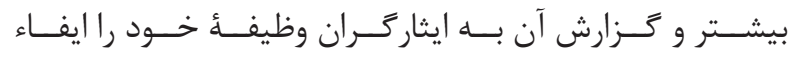

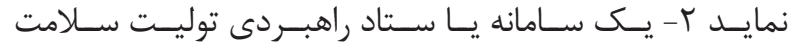

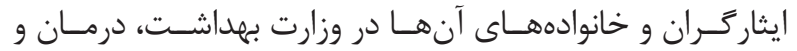

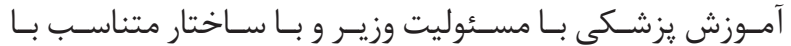

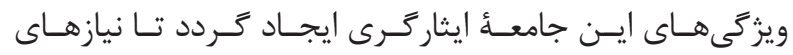

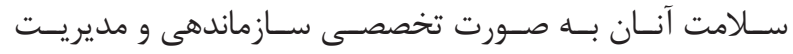

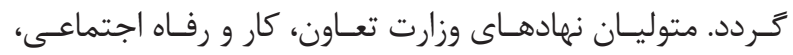

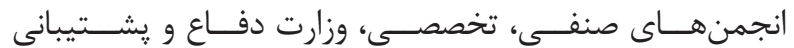

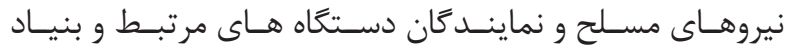

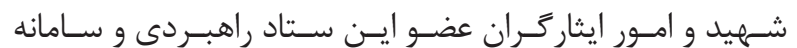

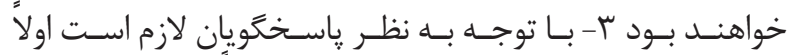

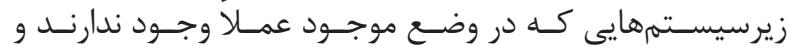

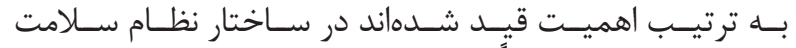

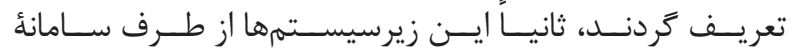

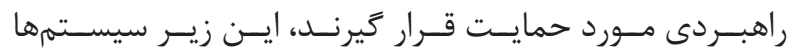

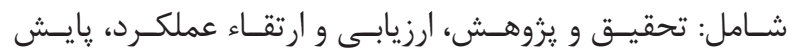

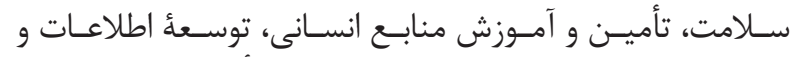

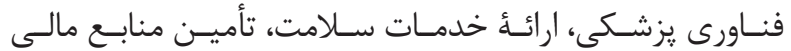

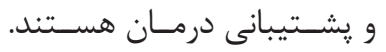

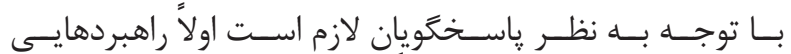

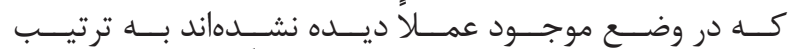

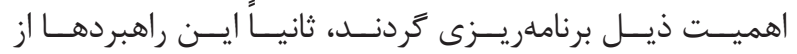

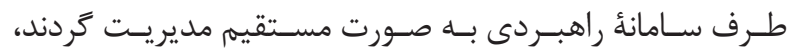

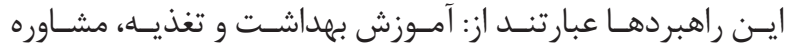

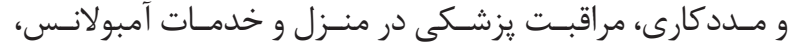

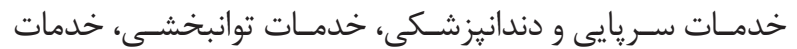

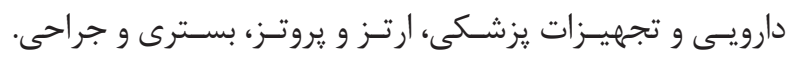

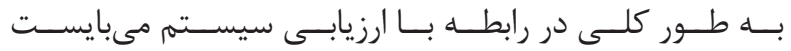

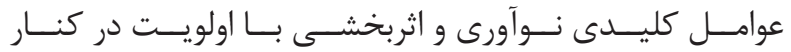

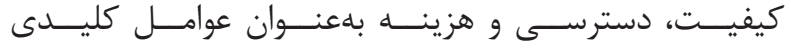

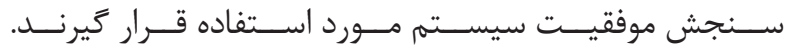

\section{Quran Karim. $2^{\text {nd }}$ ed. Qom. 2005.}

2. Shojapour S, dadmarzi SM, Habibi mazaheri M, Amini M. Set of rules and regulations veterans and their families of martyrs, missing and captives. $2^{\text {nd }}$ ed. Department of veterans and their families support and welfare services. 1992.

3. Department of management development and parliamentary affairs martyr foundation and veterans affairs. Veterans comprehensive set of rules and regulations. $1^{\text {st }}$ ed. Shahed Publication. 2007.

4. The Third Development Plan. Article 37. Part C.

5. Legal vice presidency. Fifth five-year development plan of the islamic republic. $3^{\text {nd }}$ ed. 2011.

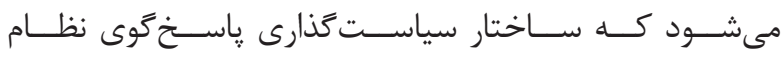

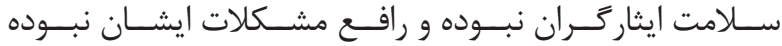

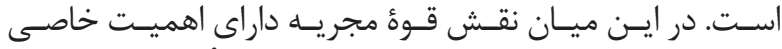

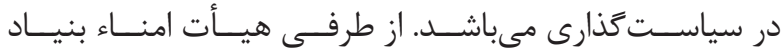

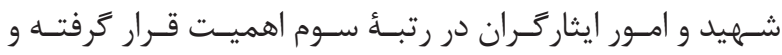

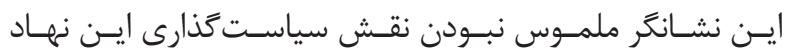

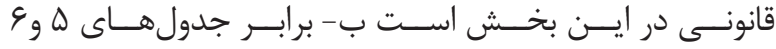

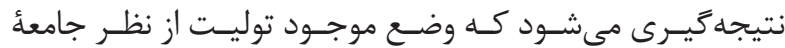

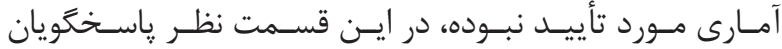

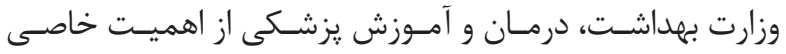

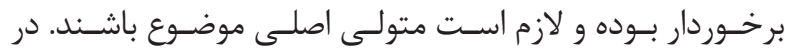

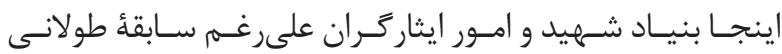

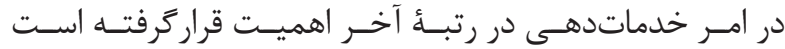

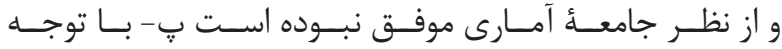

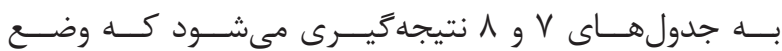

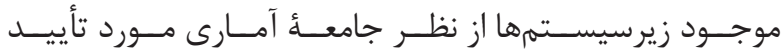

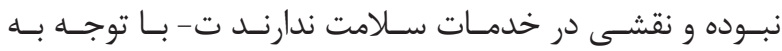

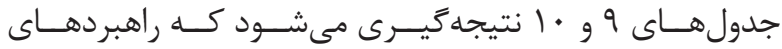

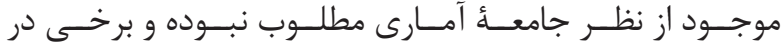

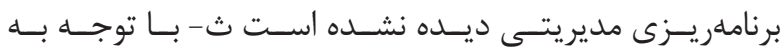

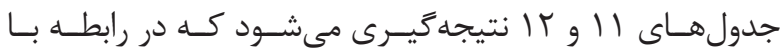

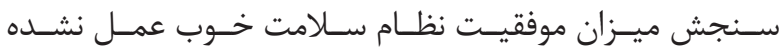

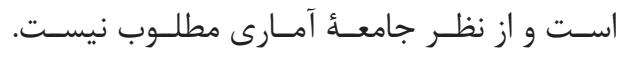

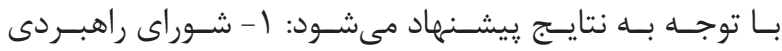

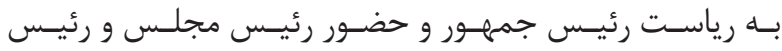

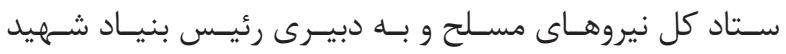

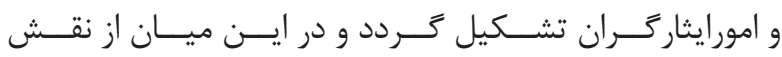

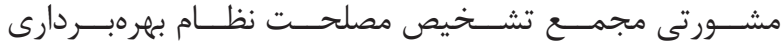

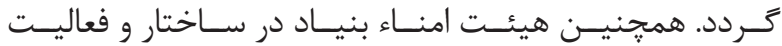

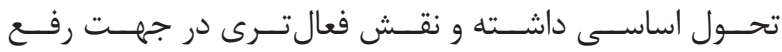

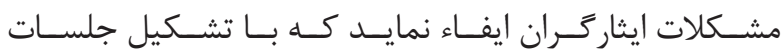

\section{منابع}

6. Linda SE, Jack D, Peter GM. Strategic management of health care organization. Singapore. Pub:Blakwell. 2008.

7. Cultural department of veterans affairs martyrs foundation. Veterans affairs macro approach martyr Foundation. 2008.

8. Medical council of islamic republic of Iran. Journal of Medical Council. 2014.

9. Firozabadi H, farhadi M. The effect of Basij culture on national security. Strategic Defense Studies. 2010.

10. Marofi F. The basic principles of strategic management. Centre for publishing academic books. 2003.

11. Birami MH, Strategic management, implementation 
and control. Industrial Management Institute. 2013.

12. Safari M, Shijaeezadeh D, Ghofranipour F, heidarnia A, Pakpour H. Theories and methods of health education, health promotion. 2nd ed. Asar Sobhan Publication. 2012.

13. Tarighat monfared M, Akhavan behbahani A, Hassanzadeh A. National health principles. Majlis research center. Negaran Shahr Publication. 2008.

14. United Nation. Human development report. United Nations Press. 2005.

15. Ghalibaf M. Strategic approach to health system. $1^{\text {st }}$ ed. Negarestan Hamed Publication. 2011.

16. Deputy Health martyr Foundation and Veterans Affairs. $1^{\text {st }}$ ed. 2009.

17. http://farsi.khamenei.ir.
18. Medical Council of islamic republic of Iran. Journal of Medical Council, 16. 2014.

19. Parsian A, Erabi M. strategic Management. 5nd ed. Cultural research bureau Publication. 2003.

20. Moazen Jami MH, Rafie Far S, Motlagh ME, Foladvand Z. Strategic management of health care organizations. Nashre shahr Publication. 2010.

21. Johnson JA, Stoskopf C. Comparative health systems: global perspectives. $1^{\text {st }}$ ed. Jones \& Bartlett learning. 2011.

22. The supreme national Defense University. Iranian strategic model for islamic progress. The Supreme National Defense University Publication. 2009.

23. Goldasteh A. Principles of teaching analysis software SPSS15. Hami Publication. 2008. 